\title{
Custos das Empresas de Construção Civil listadas na B3 em períodos de Crise e de Prosperidade Econômica
}

Guilherme Lima dos Santos Bacharelado em Ciências Contábeis pela Universidade Federal de Alagoas - UFAL Analista Contábil Avenida Deputada Selma Bandeira, 242. Antares. Maceió/AL. CEP: 57.083-630 E-mail: guilhermelimsa@hotmail.com

Valdemir da Silva

Mestrado em Ciências Contábeis pela Universidade Federal de Pernambuco - UFPE Professor na Universidade Federal de Alagoas - UFAL e na Faculdade de Economia, Administração e Contabilidade - FEAC Av. Lourival Melo Mota, S/N. Tabuleiro do Martins. Maceió/AL.CEP: 57.072-900 E-mail:valdemir.silva@feac.ufal.br

Cleiton Rodrigo Buarque Silva Pós-Graduação em Gestão de Negócios, Controladoria e Finanças Corporativas pelo Instituto de Pós-Graduação e Graduação Analista Contábil Rua São Francisco de Assis, 1806. Jatiúca. Maceió/AL. CEP: 57.035-680 E-mail: cleiton_rodrigo2006@hotmail.com

Kleber Luis Alves Guedes Doutorado em andamento em Ciências Contábeis pela Fucape Business School Professor Adjunto na Universidade Federal de Alagoas - UFAL e na Faculdade de Economia, Administração e Contabilidade - FEAC Av. Lourival Melo Mota, S/N. Tabuleiro do Martins. Maceió/AL.CEP: 57.072-900 E-mail:kla.guedes@hotmail.com

Natallya de Almeida Levino Doutorado em Engenharia da Produção pela Universidade Federal de Pernambuco UFPE Professora na Universidade Federal de Alagoas - UFAL e na Faculdade de Economia, Administração e Contabilidade - FEAC Av. Lourival Melo Mota, S/N. Tabuleiro do Martins. Maceió/AL.CEP: 57.072-900 E-mail: natallya.levino@feac.ufal.br

\section{RESUMO}

Motivado pela importância que a indústria da construção civil possui para a economia do País, este estudo busca investigar os custos de empresas do setor da construção civil, listadas na B3, em períodos de prosperidade econômica (2010-2013) e de crise 
Custos das Empresas de Construção Civil listadas na B3 em períodos de Crise e de Prosperidade Econômica

Guilherme Lima dos Santos, Valdemir da Silva, Cleiton Rodrigo Buarque Silva, Kleber Luis Alves Guedes,

Natallya de Almeida Levino

econômica (2014-2018). Para alcançar o objetivo, utilizaram-se pesquisas descritivas, documental e quantitativa, bem como a coleta de dados referentes à Receita Líquida $(R L)$, ao Custo dos Produtos Vendidos (CPV), às Despesas Administrativas (DA) às Despesas de Vendas (DV) e aos custos totais da amostra correspondente à 18 empresas e, em virtude de a distribuição dos dados não ser normal, empregou-se o teste não paramétrico de wilcoxon e estatística descritiva. Os resultados da pesquisa revelaram que não houve alteração significativa entre os custos de venda das empresas de construção civil no período de prosperidade econômica e de crise econômica, porém, para os outros indicadores $D A / R L$, $D V / R L$ e $C T / R L$, houve perda de desempenho econômico no período de crise econômica. Além disso, a dinâmica dos custos mostrou, por meio da análise descritiva, o comprometimento médio da receita líquida em relação aos custos totais que inclinaram de $87 \%$, no período prosperidade econômica, para 118\%, nos quatro anos de crise econômica, indicando, assim, prejuízo. Esta pesquisa revela assim novas informações para que os gestores vislumbrem caminhos para decisões mais assertivas, buscando manter a continuidade operacional dessas organizações no mercado.

Palavras-chave: Custos. Construção Civil. Prosperidade. Crise econômica.

Costs of B3 Civil Construction Companies in periods of Crisis and Economic Prosperity

\section{ABSTRACT}

Motivated by the importance that civil construction industry has for the country's economy, this study aimed to investigate the costs of B3 civil construction companies during moments of economic prosperity (2010-2013) and of economic crisis, as well (2014-2018). To achieve this objective, descriptive, documentary, a quantitative research was performed with a collection of data related to Net Income (RL), Cost of Products Sold (CPV), Sales Costs (DV), Administrative Expenses (DA) and total costs (CT) of a total of 18 companies. There was a non-normal distribution of the data; thus, the non-parametric Wilcoxon test and descriptive statistics were used. The results obtained in this study showed there was no significant change in the sales costs of civil construction companies when compared in both analyzed periods (prosperity and crisis); however, for the other indicators (DA/RL, DV/RL, and CT/RL), there was an economical loss in the period of economic crisis. Moreover, through a descriptive analysis the dynamics of costs showed an average impairment of net incomes in comparison to the total costs, which increased from $87 \%$ in the period of economic prosperity to $118 \%$ in the four years of economic crisis, thus indicating a loss. This research thus reveals new information so that managers can envisage ways for more assertive decisions, with the purpose of maintaining the operational continuity of these organizations in the market. 
Custos das Empresas de Construção Civil listadas na B3 em períodos de Crise e de Prosperidade Econômica Guilherme Lima dos Santos, Valdemir da Silva, Cleiton Rodrigo Buarque Silva, Kleber Luis Alves Guedes, Natallya de Almeida Levino

Keywords: Costs. Civil Construction. Prosperity. Economic Crisis.

\section{Costos de las Empresas de Construcción Civil B3 em Periodos de Crisis y Prosperidad Económica}

\section{RESUMEN}

Motivado por la importancia que tine la indústria de la construcción civil para la economía del país, este estudio tuvo como objetivo investigar los costos de las empresas de construcción civil B3 en períodos de prosperidad económica (2010-2013) y crisis económica (2014-2018). Para lograr este objetivo se realizó una investigación descriptiva, documental y cuantitativa, así como la recolección de datos relativos a la Renta Neta (RL), Costo de Productos Vendidos (CPV), Costos de Venta (DV), Gastos Administrativos (DA) y costos totales (CT) de 18 empresas. Hubo una distribución anormal de los datos; por tanto, se utilizó la prueba no paramétrica de Wilcoxon y la estadística descriptiva. Los resultados obtenidos en este estudio mostraron que no hubo cambios significativos en los costos de venta de las empresas de construcción civil al compararlos en los dos períodos analizados (prosperidad y crisis); sin embargo, para los otros indicadores (DA / RL, DV / RL y $C T$ / $R L$ ), hubo una pérdida de desempeño económico en el período de crisis económica. Además, la dinámica de costos mostró, a través del análisis descriptivo, un deterioro promedio de los ingresos netos en comparación con los costos totales, los cuales pasaron de $87 \%$ en el período de prosperidad económica a $118 \%$ en los cuatro años de crisis económica, lo que indica una pérdida. Así, esta investigación revela nueva información para que los gerentes puedan vislumbrar formas de tomar decisiones más asertivas, buscando mantener la continuidad operativa de estas organizaciones en el mercado.

Palabras clave: Costos. Construcción civil. Prosperidad. Crisis económica.

\section{INTRODUÇÃO}

A conjuntura na qual as corporações estão inseridas obriga seus gestores a estarem inteirados cada vez mais sobre o controle gerencial da organização, o qual, por conseguinte, exige o conhecimento de qual montante de custos se adequa à necessidade da empresa que, para esse fim, empreende esforços financeiros, humanos, tecnológicos e materiais.

Sob essa perspectiva e em virtude da imposição de um mercado competitivo, a tomada de decisão deve ser eficaz e célere, conduzindo o empresário a ter, além do 
Custos das Empresas de Construção Civil listadas na B3 em períodos de Crise e de Prosperidade Econômica Guilherme Lima dos Santos, Valdemir da Silva, Cleiton Rodrigo Buarque Silva, Kleber Luis Alves Guedes, Natallya de Almeida Levino

conhecimento, apoio técnico e maior número de ferramentas que contribuem para que o processo de gestão seja desenvolvido dentro de preceitos que tenham o lucro como objetivo.

Nessa busca por resultados e pela continuidade operacional, gerir os comportamentos dos custos é considerado um mecanismo substancial para a potencialização dos resultados da empresa, ostentando importância no controle do negócio e na conservação das atividades empresariais (Rigo, Godoy, \& Scarpin, 2015). Com isso, a gestão do comportamento dos custos é fator determinante para bons resultados organizacionais (Bomfim, Callado, \& Callado, 2018).

Assim, exposta a importância da utilização de custos para gerenciar uma empresa, Richartz (2013) aponta o mérito de estudos científicos para auxiliar a compreensão do comportamento dos custos, agregando conhecimento à gama de pesquisas já existentes, que auxiliarão o tomador de decisão na direção a ser seguida pela empresa, em especial na economia brasileira, que nos últimos anos vem passando por um processo de instabilidade.

O desenvolvimento econômico de uma região é atribuído a um conjunto de elementos que elevam a riqueza de um país, o qual naturalmente aumentará o poder de compra da população local, melhorando a qualidade de vida. Esse conjunto de elementos inclui muitos setores que são vitais para o crescimento econômico nacional, destacando-se aqueles que exercem posição de grande influência tanto na economia, quanto em comunicação com diversos outros setores, citando-se, como exemplo, a indústria da construção civil (Vieira \& Nogueira, 2018).

Souza, Oliveira, Santana, Viana Neto e Santos (2015) mostram que a demanda da construção civil está diretamente ligada à posição econômica na qual o setor está inserido. Dessa forma, em períodos de prosperidade econômica, o setor apresentará bons resultados, consequentemente em períodos de crise, haverá implicações pouco agradáveis no desenvolvimento do segmento. 
Custos das Empresas de Construção Civil listadas na B3 em períodos de Crise e de Prosperidade Econômica Guilherme Lima dos Santos, Valdemir da Silva, Cleiton Rodrigo Buarque Silva, Kleber Luis Alves Guedes,

A Figura 1 apresenta o gráfico com a variação anual do valor do PIB Brasil e do PIB da Construção Civil, ambos em volume percentual. Com base nesses percentuais, identificam-se, nos períodos anteriores a 2014, as variações anuais do PIB foram todas positivas, apesar de alguns anos serem melhores e outros nem tanto, reflexo da crise financeira global de 2008.

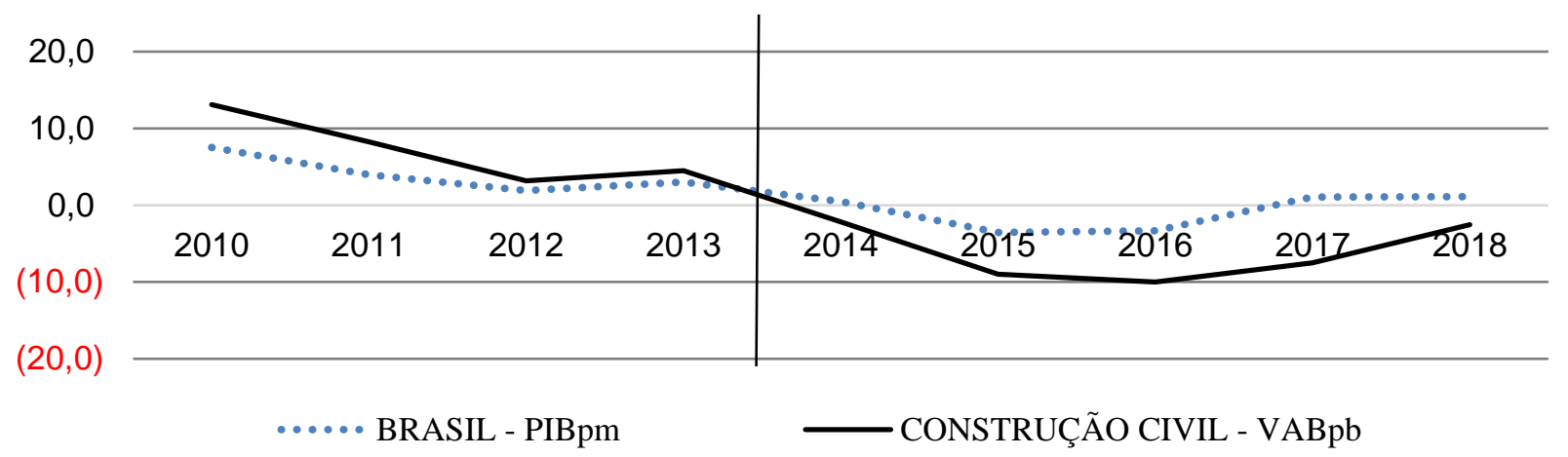

Figura 1. Comportamento do PIB Brasil x PIB Construção Civil (\%)

Fonte: Câmara Brasileira da Indústria da Construção, 2019.

Observa-se que, embora desproporcionais, existe uma correspondência entre o Produto Interno Bruto (PIB) do Brasil e o Produto Interno Bruto (PIB) da Construção Civil ao passo que aumentos e quedas são simultâneos nas variáveis apresentadas na Figura 1, uma vez que a partir de 2014, ano em que foi realizada a Copa do Mundo FIFA, ocorre o início da atual crise econômica e o PIB desse ano apresenta queda em relação ao ano anterior. Em 2015 e 2016, os valores apresentam-se negativos, caracterizando, assim, a recessão econômica. O princípio de recuperação econômica advém em 2017 com o retorno da variação positiva do PIB.

A Figura 1 também mostra que o setor da construção civil entrou em declínio econômico até 2018, apresentando variação negativa de 2014 a 2018, revelando pior resultado em 2016 cuja retração foi de $-10 \%$.

O comportamento do PIB da Construção Civil também sinaliza para a média da taxa anual de desemprego, a qual revela-se abaixo 7,5\%, nos 2010 a 2014, elevando- 
Custos das Empresas de Construção Civil listadas na B3 em períodos de Crise e de Prosperidade Econômica Guilherme Lima dos Santos, Valdemir da Silva, Cleiton Rodrigo Buarque Silva, Kleber Luis Alves Guedes, Natallya de Almeida Levino

se a partir de 2015 para percentuais acima de $8,5 \%$ e teve o seu auge em 2017 , uma ano após as olimpíadas, alcançando o recorde de 12,7\% (IBGE, 2020).

Dessa maneira, a pertinência do conhecimento sobre comportamento de custos destacada nesta parte introdutória que aborda essa temática, conjugada à relevância do setor da construção civil na economia brasileira, motiva o problema em questão: Como se comportaram os custos das empresas de Construção Civil listadas na B3 em Períodos de Crise e Prosperidade Econômica?

O objetivo geral desta pesquisa é investigar o comportamento dos custos das empresas de Construção Civil listadas na B3 em períodos de prosperidade e crise econômica.

Esta pesquisa é justificada por evidenciar a importância que o setor de construção civil possui para a economia do País, uma vez que, além da amplitude de sua dimensão econômica e social, suas atividades relacionam-se de forma direta com a economia, sendo uma grande geradora de emprego, renda e tributos (Teixeira \& Carvalho, 2005).

A indústria da construção, nos últimos nove anos, conheceu dos períodos econômicos divergentes: a economia em crescimento e o ramo da construção civil apresentando uma intensa expansão de seus negócios; mas, em outro momento mais recente, emerge a desaceleração da economia, a qual também contribuiu para o declínio econômico setor (Umpieres, 2016).

Considerando a significância do setor da construção civil para a economia nacional e o estreitamento econômico das empresas que o compõem, investigar o comportamento dos custos nos períodos de inclinação e declínio econômicos torna-se relevante, visto que as evidencias encontradas interessam a outros setores com os quais as empresas de construção civil transacionam, bem como a diversos investidores. Por isso, para melhor apresentar a dinamicidade do comportamento dos custos, escolheu-se observar empresas do setor da construção civil, listadas na B3. 
Custos das Empresas de Construção Civil listadas na B3 em períodos de Crise e de Prosperidade Econômica Guilherme Lima dos Santos, Valdemir da Silva, Cleiton Rodrigo Buarque Silva, Kleber Luis Alves Guedes, Natallya de Almeida Levino

O trabalho está organizado em cinco seções. A primeira seção apresenta a introdução; a segunda expõe o referencial teórico; a terceira apresenta a metodologia da pesquisa; a quarta apresenta a análise dos dados e os resultados; por fim, a última seção, apresenta as considerações finais.

\section{REFERENCIAL TEÓRICO}

Esta seção, visando reforçar teoricamente o objetivo desta pesquisa, apresenta pontos sobre a Construção Civil no cenário nacional, comportamento dos custos e uma exposição de estudos anteriores.

\subsection{Construção Civil no cenário brasileiro}

Paiva e Ribeiro (2005) informam que qualquer atividade humana necessita de um ambiente devidamente construído para desenvolver suas atividades. Assim, percebe-se que o segmento da construção, ao passo que constrói os espaços onde estão tudo aquilo que tem vida, é substancialmente importante.

Contribuindo com esse pensamento, Scramin (2012) afirma que a construção civil é a parte da engenharia que contribui de maneira expressiva para a sobrevivência do ser humano, assistindo a população em necessidades fundamentais, oferecendo emprego e renda, infraestrutura e moradia, pondo a construção civil em evidência num cenário econômico-social, à medida que oferece condições dignas de sobrevivência ao exercer suas atividades.

Dessa forma, define-se a construção civil como um segmento que compreende as atividades de instalação, reparação e equipamentos que as obras necessitam, de modo que a atividade de construir abrange dimensões que abarcam ações além da própria construção, tendo sua significância em meios sociais e econômicos (Scramin, 2012). 
Custos das Empresas de Construção Civil listadas na B3 em períodos de Crise e de Prosperidade Econômica Guilherme Lima dos Santos, Valdemir da Silva, Cleiton Rodrigo Buarque Silva, Kleber Luis Alves Guedes, Natallya de Almeida Levino

Assim, percebe-se que a não limitação da construção civil para apenas o seu produto final provoca impacto deste setor em outros que são significativamente importantes dentro de um contexto econômico nacional.

Nessa perspectiva, o segmento de edificações se apresenta como um dos mais proativos na economia brasileira, mostrando grande poder em gerar riqueza, ao passo que se consegue identificar que obras realizadas em determinado território movimentam capital dentro daquele contexto, ratificando a importância de empresas de edificações, independentemente do tamanho, na formação do cidadão com mínimo de decência (Paiva \& Ribeiro, 2005).

Esse contexto tem ficado cada vez mais em evidência, quando se percebe que 0 fechamento das empresas do ramo da construção e as consequências afetam os mercados de trabalho e financeiro, crescendo o desemprego e diminuindo investimento, contribuindo na exposição da crise vivida no Brasil (Serrado, Santos, Oliveira, Jesus, \& Netto, 2017).

Desse modo, para Câmara Brasileira da Indústria da Construção Civil - CBIC (2020), embora apresente posição de destaque em momentos insatisfatórios, o cenário da construção civil tem sido motivo de preocupação, pois, tem se observado uma queda nos números do segmento de edificações. Essa queda é fielmente representada por meio da Figura 2 que demonstra a taxa de variação do PIB da construção civil.

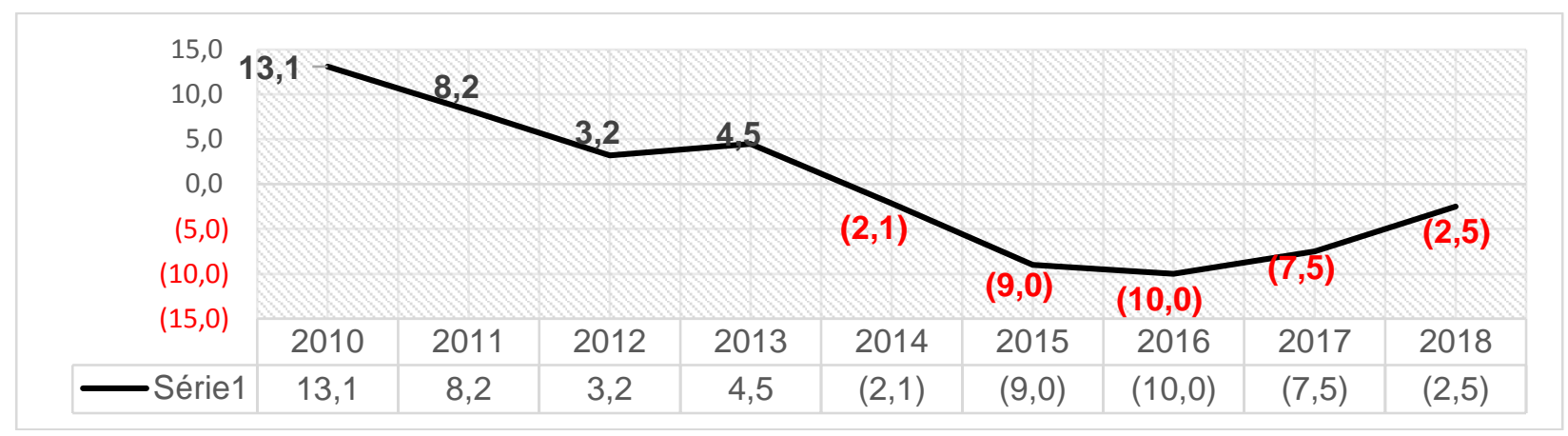

Figura 2. Taxa de variação do PIB da Construção Civil 
Custos das Empresas de Construção Civil listadas na B3 em períodos de Crise e de Prosperidade Econômica Guilherme Lima dos Santos, Valdemir da Silva, Cleiton Rodrigo Buarque Silva, Kleber Luis Alves Guedes, Natallya de Almeida Levino

Fonte: Dados da Câmara Brasileira da Indústria da Construção Civil, 2020.

Observa-se que, nos anos analisados, houve quedas significativas entre $2014 \mathrm{e}$ 2018, as quais revelam números negativos, embora, ainda abaixo de zero, seja constatada uma sensível melhora de 2016 para 2018.

Assim, Fernandes, Matsuoka e Costa (2018) reforçam que a indústria da construção tem que acompanhar a modernização do mercado, a fim de minimizar a perda de recursos essenciais para a produção, principalmente em momentos de crise.

\subsection{Comportamento dos Custos}

Comportamento de custo é a forma pela qual os gastos operacionais se modificam em função de determinada variável. Tal variável pode ser o volume de vendas, o nível de atividades ou influências externas às empresas (Richartz, Borgert, \& Lunkes, 2014).

Garrison, Noreen e Brewer (2013) reforçam conceituando que o comportamento de custos é a reação de um gasto operacional a um nível de atividade, assim, analisar o comportamento de custos é identificar qual custo está se modificando em relação ao que é produzido e em qual proporção.

As técnicas de gestão associadas ao controle dos custos são ligadas à essência dos fatores operacionais da atividade econômica a qual a empresa está inserida. Desse modo, depreende-se que entender como se comportam os custos é entender a operacionalização de determinado setor (Callado \& Pinho, 2014).

Embora os custos estejam ligados à operação da empresa, a compreensão comportamento dos custos, segundo Araújo, Mendes e Martins (2018), serviria também para identificar se a ideia de um empreendimento seria viável. Por isso, os gerentes que compreendem como funciona o comportamento de custos poderão antecipar a sua visão em relação ao caminho que o custo deverá percorrer, facilitando sua gestão e, por conseguinte, aumentar o lucro (Medeiros, Costa, \& Silva, 2005). 
Custos das Empresas de Construção Civil listadas na B3 em períodos de Crise e de Prosperidade Econômica Guilherme Lima dos Santos, Valdemir da Silva, Cleiton Rodrigo Buarque Silva, Kleber Luis Alves Guedes, Natallya de Almeida Levino

Assim, para uma boa gestão, o responsável pela tomada de decisão deverá ter como pré-requisitos conhecimentos sobre fatores relacionados a custos que estão diretamente ligados à continuidade da empresa, tais quais: Métodos de Custeio; Sistemas de predeterminação de custos; Análise de determinantes de custos; Custeio por ciclo de vida; Análise de cadeia de valor e; Gestão baseada em atividades (Machado \& Souza, 2006).

Dando continuidade, Paulino (2012) reforça que a apuração e controle de custos é uma das técnicas especializadas de gestão que facilitam às empresas permanecerem no mercado de maneira estável e conseguirem enfrentar desafios recorrentes no mercado competitivo.

Xavier Filho (2019) acrescentam que a importância de entender a maneira como se comportam os custos das empresas ainda auxilia o gestor a tomar decisões e observar com maior clareza as imperfeições na entidade, atribuindo à organização vantagem sobre as demais, visto que a visão técnica do comportamento dos gastos na produção condicionará a sua gestão.

Silva, Zonatto, Magro e Klann (2019) explicam brevemente como se comportam os gastos operacionais, esclarecendo que custos se dividem em fixos e variáveis, sendo suas alterações associadas ao nível de atividade da empresa.

Custo variável é aquele cujo consumo aumenta de acordo com o volume de produção, aumentando proporcionalmente aos itens fabricados, sendo nulo quando o volume de fabricação for igual a 0 (Martins, 2003). Já os custos fixos, independentemente da variação da produção, será sempre o mesmo em determinado período, sendo um contraste dos custos variáveis, mantendo-se constante ainda que o nível de fabricação aumente de forma relevante (Vanderbeck \& Nagy, 2001).

No entanto, não se sabe se gestores percebem o comportamento dos custos da maneira devida, por isso, também não se sabe se incorporam os dados obtidos da fábrica às informações que precedem a tomada de decisão (Bradbury \& Scott, 2013). 
Custos das Empresas de Construção Civil listadas na B3 em períodos de Crise e de Prosperidade Econômica Guilherme Lima dos Santos, Valdemir da Silva, Cleiton Rodrigo Buarque Silva, Kleber Luis Alves Guedes, Natallya de Almeida Levino

Vale ressaltar também que os custos geralmente são altos e escassos, fatores que dificultam e elevam a importância de controlar os gastos de produção, que seria sugestão à competitividade (Ezekiel, Adebayo, \& Osemense, 2019).

Assim, constata-se que gastos operacionais não são exclusivamente influenciados por fatores internos, mas pelo contexto que a empresa está inserida, revelando, assim, que o entendimento do comportamento dos custos requer atenção a fatores não somente internos (Silva et al., 2019)

Nota-se, então, dificuldades reais existentes para analisar comportamentos de custos, assim como suas variáveis, entretanto, compreende-se também total dependência entre o conhecimento de custos e diversas finalidades ligadas à tomada de decisão da empresa (Richartz et al., 2013).

\subsection{Estudos Anteriores}

A compreensão do comportamento dos custos nas organizações não é uma tarefa tão simples de ser realizada. Diante desse óbice, Magalhães, Elias, Ferreira e Borgert (2017), De Oliveira et al. (2019), Ludwing, Borgert e Kremer (2016) e Silva, Leal e Trindade (2015) realizaram estudo com objetivo de investigar custos empresariais, inclusive de entidades de listadas na BM\&FBOVESPA, porém os resultados mostram que, diante das dificuldades encontradas para a sua compreensão, não existe um consenso para explicar o comportamento dos custos empresariais.

Magalhães et al. (2017) identificaram e analisaram o comportamento dos custos, despesas e margem de lucro das empresas do segmento de calçados listadas na BM\&FBOVESPA durante o período de 2007 a 2016. A mostra compreendeu 3 empresas do setor Consumo Cíclico e subsetor Tecidos, Vestuário e Calçados. Este estudo revelou que os gastos com pessoal, os custos dos produtos vendidos, as despesas administrativas e com vendas, os custos totais e a margem de lucro não se alteraram com as medidas de desoneração da folha de pagamento. 
Custos das Empresas de Construção Civil listadas na B3 em períodos de Crise e de Prosperidade Econômica Guilherme Lima dos Santos, Valdemir da Silva, Cleiton Rodrigo Buarque Silva, Kleber Luis Alves Guedes, Natallya de Almeida Levino

De Oliveira, David, da Silva, Guedes e Correia (2019) pesquisaram o comportamento dos custos das empresas do ramo da construção civil, listadas no Brasil, Bolsa, \& Balcão (B3) entre 2008 e 2017. A amostra compreendeu 18 companhias abertas e os resultados anunciaram que as entidades analisadas possuem uma estrutura de custos similar, visto que, nos 10 anos investigados, em média, $76 \%$ da Receita Líquida de Vendas (RLV) dessas empresas foram destinados a cobrir o custo dos produtos vendidos (CPV). Analisando-se a média dos insumos (custos e despesas) em relação à $R L V$, observou-se que existe uma grande ligação entre eles, pois à medida que a receita líquida de vendas varia, os custos e despesas se alteram no mesmo sentido. Além disso, observou-se também que os melhores resultados foram apresentados entre os anos de 2008 e 2013 e que, entre os anos de 2014 e 2017, os resultados do ramo da construção civil declinaram.

Ludwing, Borgert e Kremer (2016) verificaram se houve redução dos custos em duas empresas analisadas do segmento da construção civil, num período equitativo antes (nov/12 a out/13) e depois (nov/13 a out/14) da desoneração da folha de pagamento. A amostra comportou 2 empresas do setor de construção. Os resultados evidenciaram que a empresa que utiliza mão de obra própria obteve benefícios com a alteração da legislação, entre eles a redução do valor pago à previdência, enquanto, na empresa que detém mão de obra terceirizada, os benefícios não foram verificados, nem de modo indireto.

Silva, Leal e Trindade (2015) investigaram os custos nas empresas listadas na BM\&F Bovespa, no segmento de carnes e derivados, entre 2004 a 2013. A amostra compreendeu as empresas JBS, Marfrig, Excelsior, Minerva, Minupar e Brasil Foods. Os resultados revelaram que, na análise do segmento de carnes e derivados, $76 \%$ da Receita Líquida de Venda (RLV) destinam-se a cobrir o Custo do Produto Vendido (CPV) no período de 10 anos analisados. $\mathrm{Na}$ análise da correlação, confirmou-se que existe forte correlação entre o CPV e RLV, o que demonstra que no segmento a 
Custos das Empresas de Construção Civil listadas na B3 em períodos de Crise e de Prosperidade Econômica Guilherme Lima dos Santos, Valdemir da Silva, Cleiton Rodrigo Buarque Silva, Kleber Luis Alves Guedes, Natallya de Almeida Levino

alteração RLV tem associação significativa no aumento do CPV, o que poderá influenciar no desempenho das empresas.

\section{METODOLOGIA DA PESQUISA}

Esta seção visa apresentar pontos que esclarecem a classificação metodológica e a amostra da pesquisa, bem como a coleta e tratamento dos dados.

\subsection{Classificação da Pesquisa}

A pesquisa, quanto aos objetivos, é caracterizada como descritiva, a qual, segundo Pamplona, Leite e Zonatto (2018), refere-se a não manipulação das variáveis observadas. Dessa forma, a fim de analisar como se comportam os custos de empresas do setor da construção civil num determinado contexto econômico, o estudo buscou uma observação sem que houvesse qualquer tipo de alteração das variáveis.

Quanto à abordagem, a pesquisa é delineada como quantitativa uma vez que, consoante Pádua (2012), busca as relações entre as variáveis estudadas por meio de uma verificação, com a finalidade de desenvolver hipóteses que possam ser entendidas como lei geral, possibilitando previsões a partir dos dados encontrados. Assim, o presente estudo utiliza ferramentas estatísticas para relacionar as variáveis e atingir os objetivos propostos.

Além disso, o estudo é documental, já que se fez necessário a busca e o uso de documentos. Para Kripla, Scheller e Bonotto (2015), a pesquisa documental é o tipo de investigação que extrai dados puramente de documentos, buscando compreender um fenômeno por intermédio da extração de informações que estão contidas nos documentos analisados.

\subsection{Amostra da Pesquisa}

A pesquisa compreendeu uma amostra de 18 empresas do setor de construção civil listadas na B3, as quais estão expostas no Quadro 1. 
Custos das Empresas de Construção Civil listadas na B3 em períodos de Crise e de Prosperidade Econômica Guilherme Lima dos Santos, Valdemir da Silva, Cleiton Rodrigo Buarque Silva, Kleber Luis Alves Guedes,

\begin{tabular}{|c|l|l|}
\hline Ordem & \multicolumn{1}{|c|}{ Razão social } & \multicolumn{1}{|c|}{ Nome de Pregão } \\
\hline 1 & CONSTRUTORA ADOLPHO LINDENBERG S.A. & CONST A LIND \\
\hline 2 & CONSTRUTORA TENDA S.A. & TENDA \\
\hline 3 & CR2 EMPREENDIMENTOS IMOBILIARIOS S.A. & CR2 \\
\hline 4 & CYRELA BRAZIL REALTY S.A. EMPREEND E PART & CYRELA REALT \\
\hline 5 & DIRECIONAL ENGENHARIA S.A. & DIRECIONAL \\
\hline 6 & EVEN CONSTRUTORA E INCORPORADORA S.A. & EVEN \\
\hline 7 & EZ TEC EMPREEND. E PARTICIPACOES S.A. & EZTEC \\
\hline 8 & GAFISA S.A. & GAFISA \\
\hline 9 & HELBOR EMPREENDIMENTOS S.A. & HELBOR \\
\hline 10 & JHSF PARTICIPACOES S.A. & JHSF PART \\
\hline 11 & JOAO FORTES ENGENHARIA S.A. & JOAO FORTES \\
\hline 12 & MRV ENGENHARIA E PARTICIPACOES S.A. & MRV \\
\hline 13 & PGD REALTY S.A. EMPREEND E PARTICIPACOES & PDG REALT \\
\hline 14 & RNI NEGOCIOS IMOBILIARIOS S.A. & RNI \\
\hline 15 & ROSSI RESIDENCIAL S.A. & ROSSI RESID \\
\hline 16 & TECNISA S.A. & TECNISA \\
\hline 17 & TRISUL S.A. & TRISUL \\
\hline 18 & VIVER INCORPORADORA E CONSTRUTORA S.A & VIVER \\
\hline
\end{tabular}

Quadro 1. Empresas que compõe a amostra da pesquisa Fonte: Elaborado pelos autores, 2019.

As empresas de construção civil listadas acima compõem um dos chamados setores cíclicos da B3, o qual depende de uma conjuntura econômica favorável, mostrando que quando o emprego e a renda estão em alta, as ações das empresas listadas sobem. Todavia, os momentos de baixa no emprego e no crédito sinalizam um ciclo econômico desfavorável devido ao baixo consumo. Essa correlação com o cenário econômico do país motiva reforçar a intenção de analisar os comportamentos dessas entidades.

Neste trabalho, além do setor, optou-se também por analisar empresas com dados individuais, por considerar a possibilidade de resultados que não sejam inerentes ao do segmento. 
Custos das Empresas de Construção Civil listadas na B3 em períodos de Crise e de Prosperidade Econômica Guilherme Lima dos Santos, Valdemir da Silva, Cleiton Rodrigo Buarque Silva, Kleber Luis Alves Guedes, Natallya de Almeida Levino

\subsection{Coleta e Tratamento dos Dados}

Para a coleta de dados, realizada uma busca a fim de selecionar um setor que representasse com fidelidade o movimento da economia no contexto nacional e percebeu-se que o setor de Construção Civil se adequava às características desejadas.

Dessa forma, através do site da B3 foi possível buscar informações sobre cada empresa listada no setor escolhido. Assim, coletou-se das 18 empresas de construção civil que negociam suas ações na B3.

Os indicadores investigados são Custo do Produto Vendido (CPV), Despesa Administrativa (DA) e Despesa de Vendas (DV), além dos Custos Totais (CT) que correspondem à soma do CPV, com a DA e DV. A escolha desses indicadores revelase pelo fato de as suas relações com a receita liquida evidenciarem o comportamento dos custos operacionais e não operacionais, bem como o quanto cada um consome das referidas receitas.

O Quadro 2 apresenta a operacionalização e o comportamento dos indicadores objetos de estudo.

\begin{tabular}{|c|c|c|c|}
\hline Indicador & Operacionalização & Comportamento & Autores \\
\hline$\frac{\mathrm{CPV}}{\mathrm{RL}}$ & $\begin{array}{c}\text { Indica o quanto os custos de } \\
\text { venda representam da receita } \\
\text { líquida. }\end{array}$ & $\begin{array}{c}\text { Quanto menor melhor para } \\
\text { o resultado econômico da } \\
\text { empresa. }\end{array}$ & De Oliveira et al. (2019) \\
\hline$\frac{\mathrm{DA}}{\mathrm{RL}}$ & $\begin{array}{c}\text { Indica o quanto as despesas } \\
\text { administrativas representam } \\
\text { da receita líquida. }\end{array}$ & $\begin{array}{c}\text { Quanto menor melhor para } \\
\text { o resultado econômico da } \\
\text { empresa. }\end{array}$ & Oliveira et al. (2018) \\
\hline $\mathrm{DV}$ & $\begin{array}{c}\text { Indica a parcela da receita } \\
\text { líquida correspondente às } \\
\text { despesas de vendas. }\end{array}$ & $\begin{array}{c}\text { Quanto menor melhor para } \\
\text { o resultado econômicos da } \\
\text { empresa. }\end{array}$ & Richartz et al. (2012) \\
\hline$\frac{\mathrm{CT}}{\mathrm{RL}}$ & $\begin{array}{c}\text { Indica a parcela da receita } \\
\text { líquida correspondente aos } \\
\text { custos totais. }\end{array}$ & $\begin{array}{c}\text { Quanto menor melhor para } \\
\text { o resultado econômicos da } \\
\text { empresa. }\end{array}$ & Pamplona, Leite e \\
Zonatto (2018)
\end{tabular}

Quadro 2. Indicadores utilizados no estudo. Fonte: Elaborado pelos próprios autores, 2019.

Ressalta-se, ainda, que o período analisado foi de 2010 a 2018, dividido entre os períodos de prosperidade econômica (2010 a 2013) e o de crise econômica (2014 a 
Custos das Empresas de Construção Civil listadas na B3 em períodos de Crise e de Prosperidade Econômica Guilherme Lima dos Santos, Valdemir da Silva, Cleiton Rodrigo Buarque Silva, Kleber Luis Alves Guedes, Natallya de Almeida Levino

2018). Os dados contábeis coletados para a série temporal que compreende 9 anos foram primeiramente tabulados no MS-Excel® e, logo em seguida, atualizados pelo IPCA.

Também foi necessário aplicar estatística descritiva, através da qual se conseguiu: Média; Desvio Padrão; Teste T de significância. A aplicação da estatística abrangeu o setor, considerando todas as empresas listadas na B3 presentes nessa amostra e cada empresa especificamente.

\section{ANÁLISE DOS DADOS E RESULTADOS}

Analisados os dados e os resultados da pesquisa no que concerne ao comportamento dos custos serão apresentados a seguir.

\subsection{Análise descritiva do comportamento dos custos do setor da construção civil}

Nesta seção do estudo algumas análises estatísticas serão apresentadas. Inicialmente, verificou-se que os indicadores construídos seguiam uma distribuição de probabilidade normal. Isso se fez necessário para definir qual o teste mais apropriado na comparação das médias ou medianas (a depender do teste disponível) de cada indicador em dois instantes diferentes, 2010-2013 (prosperidade econômica) e 20142018 (crise econômica).

Com esse intuito, aplicou-se o teste de Shapiro-Wilk, e pode-se verificar que nenhum dos indicadores seguiam a distribuição normal de probabilidade, a um nível de confiança estatística de 95\% (Tabela 1). 
Custos das Empresas de Construção Civil listadas na B3 em períodos de Crise e de Prosperidade Econômica Guilherme Lima dos Santos, Valdemir da Silva, Cleiton Rodrigo Buarque Silva, Kleber Luis Alves Guedes, Natallya de Almeida Levino

Tabela 1

Teste de Shapiro-Wilk.

\begin{tabular}{lcc}
\hline Indicador & Estatística W & p-valor \\
\hline $\mathrm{CPV} / \mathrm{RL}$ & 0.5902 & $0.0000\left({ }^{* * *}\right)$ \\
$\mathrm{DA} / \mathrm{RL}$ & 0.3176 & $0.0000\left({ }^{* * *}\right)$ \\
$\mathrm{DV} / \mathrm{RL}$ & 0.6645 & $0.0000\left({ }^{* * *}\right)$ \\
$\mathrm{CT} / \mathrm{RL}$ & 0.4599 & $0.0000\left({ }^{* * *}\right)$ \\
\hline
\end{tabular}

Nota. Fonte: Elaborado com base nos dados coletados da B3, 2019.

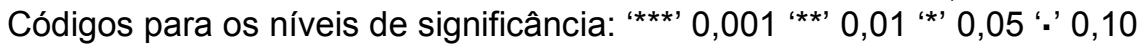

Uma vez descartado o uso da estatística paramétrica aos dados, optou-se por verificar a diferença das medianas entre os períodos, a partir de um teste não paramétrico que é o da soma de postos de Wilcoxon (W). Os resultados mostraram que não havia diferença estatística entre as medianas apenas para o indicador CPV/RL para os períodos analisados, a um nível de confiança de 95\% ( $p$-valor=0,0695), ou seja, não houve alteração significativa entre os custos das empresas de construção civil listadas na B3 no período de prosperidade (2010-2013) e no de crise econômica (20142018) (Tabela 2).

Tabela 2

Estatística descritiva dos indicadores de custos apresentados pelo setor da Construção Civil.

\begin{tabular}{|c|c|c|c|c|c|c|c|c|c|c|c|}
\hline \multirow[t]{2}{*}{ Indicador } & \multicolumn{3}{|c|}{$\begin{array}{l}\text { Período Total } \\
\text { (2010-2018) }\end{array}$} & \multicolumn{3}{|c|}{$\begin{array}{l}\text { Prosperidade } \\
\text { Econômica } \\
\text { (2010-2013) }\end{array}$} & \multicolumn{3}{|c|}{$\begin{array}{l}\text { Crise Econômica } \\
(2014-2018)\end{array}$} & \multirow[t]{2}{*}{ Teste (W) } & \multirow[t]{2}{*}{ Sig. } \\
\hline & Média & Mediana & DP & Média & Mediana & $\mathrm{DP}$ & Média & Mediana & DP & & \\
\hline CPV/RL & 0.833 & 0.730 & 0.417 & 0.746 & 0.720 & 0.197 & 0.904 & 0.740 & 0.523 & 2670.0 & 0.0695 \\
\hline $\mathrm{DA} / \mathrm{RL}$ & 0.224 & 0.105 & 0.475 & 0.110 & 0.084 & 0.088 & 0.315 & 0.137 & 0.619 & 1733.0 & $0.0000^{* * *}$ \\
\hline DV/RL & 0.089 & 0.077 & 0.077 & 0.067 & 0.061 & 0.049 & 0.106 & 0.088 & 0.091 & 1930.5 & $0.0000^{* * *}$ \\
\hline $\mathrm{CT} / \mathrm{RL}$ & 1.118 & 0.896 & 0.811 & 0.911 & 0.859 & 0.241 & 1.282 & 0.979 & 1.040 & 2022.0 & $0.0000^{* * *}$ \\
\hline
\end{tabular}

Nota. Fonte: Elaborado com base nos dados coletados da B3, 2019.

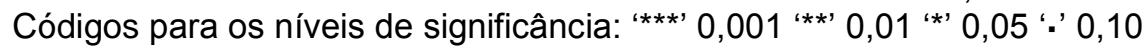


Custos das Empresas de Construção Civil listadas na B3 em períodos de Crise e de Prosperidade Econômica Guilherme Lima dos Santos, Valdemir da Silva, Cleiton Rodrigo Buarque Silva, Kleber Luis Alves Guedes, Natallya de Almeida Levino

Entretanto, para todos os outros indicadores, DA/RL, DV/RL e CT/RL, as medianas são estatisticamente diferentes a um nível de confiança inferior a 1\%. Em outras palavras, houve perda de desempenho nos períodos de crise econômica.

Analisando a relação $\mathrm{CPV} / \mathrm{RL}$, no segmento de construção civil da $\mathrm{B} 3$, entre 2010 e 2018. De acordo com os dados da tabela 2, observa-se que as 18 empresas analisadas comprometeram em média $83 \%$ da sua Receita Líquida de Vendas com o Custo dos Produtos Vendidos. Com isso, a margem que sobra para cobrir as demais despesas e para a formação do lucro é reduzida. Mesmo assim, não se pode afirmar que esse cenário foi impactado pela atual crise econômica, pois o teste de Wilcoxon não nos permite.

Da relação entre as $\mathrm{DA}$ e a $\mathrm{RL}$, os valores médios encontrados, para as 18 empresas do setor, entre 2010 e 2018, indicam que os gastos administrativos representam 0,22 da RL. Esses gastos ganharam inclinação nos últimos 4 anos de crise econômica, uma vez que a média das despesas administrativas transitou de 0,11 , no período de prosperidade econômica, para 0,31 da $R L$, nos 4 anos de crise econômica analisados. Tal situação pode ter sido motivada não somente em virtude do declínio da receita, mas também por causa da manutenção de gastos administrativos fixos estruturais.

As despesas de vendas (DV), para a série temporal investigada, correspondem, em média, a $9 \%$ da RL. Apesar de baixos, existe uma alteração significativa de um período para outro, passando de 7\% para 11\% em média.

Os custos totais (CT) das empresas de construção civil, listadas na B3 e investigadas por esta pesquisa, representavam em média, entre 2010 e 2013, antes da crise econômica, 0,91 da RL. Entretanto, nos quatro anos seguintes, a média dos custos totais das empresas foi elevada para 1,28 de comprometimento da RL com um coeficiente de variação de $81 \%$. Essa alta variabilidade da relação dos custos totais em relação à receita líquida, no período de crise econômica, contribuiu para que a média dos custos totais do período analisado (2010-2018) comprometesse 1,12 da RL. Isso 
Custos das Empresas de Construção Civil listadas na B3 em períodos de Crise e de Prosperidade Econômica Guilherme Lima dos Santos, Valdemir da Silva, Cleiton Rodrigo Buarque Silva, Kleber Luis Alves Guedes, Natallya de Almeida Levino

indica que boa parte das empresas apresentaram prejuízo, sobretudo, no período de crise econômica.

Quando observado os dados do setor, observa-se que, em geral, o comportamento é similar, havendo perda de desempenho operacional pelas organizações no período de crise econômica, com exceção, apenas, para as medianas da relação $\mathrm{CPV} / \mathrm{RL}$.

O Gráfico 4 apresenta, em geral, o desempenho dos 4 indicadores pesquisados.

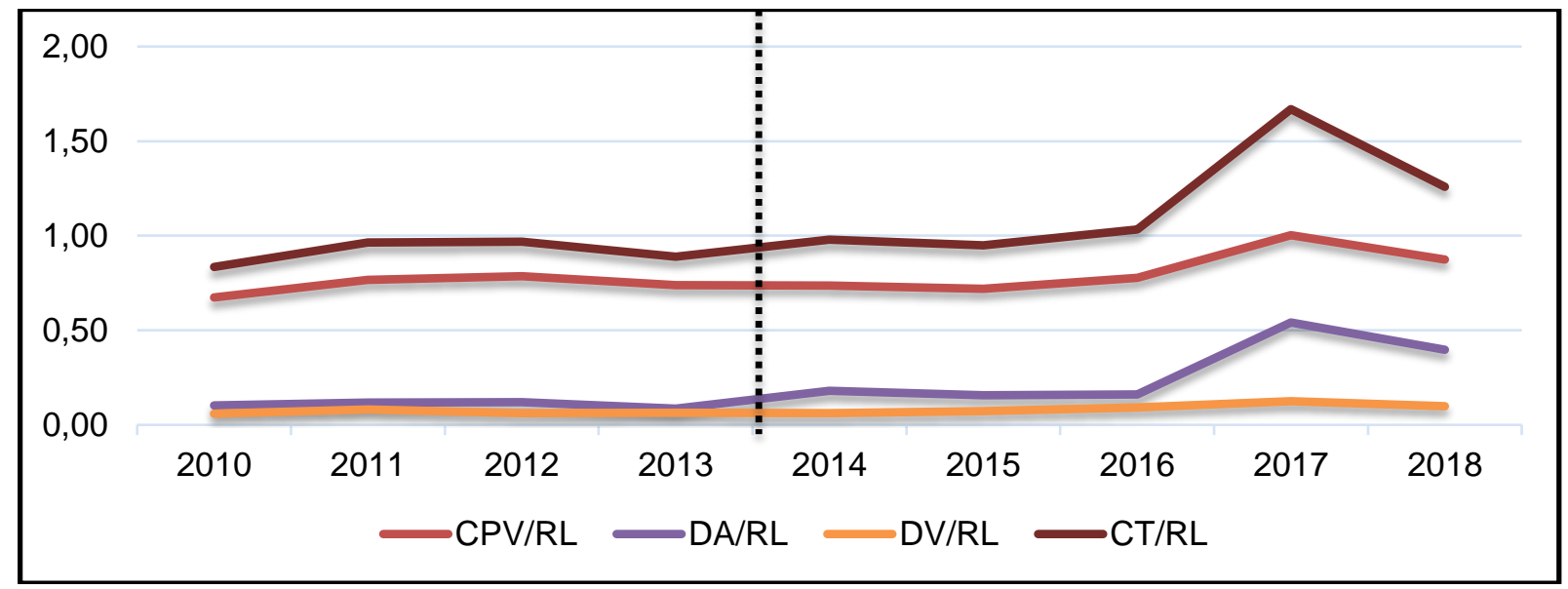

Gráfico 1. Desempenho dos Indicadores

Fonte: Elaborado com base nos dados coletados da B3, 2019.

O Gráfico 1 ilustra a evolução dos custos e despesas totais do setor da construção, principalmente, de 2016 para 2017.

\subsection{Análise do comportamento dos Custos de cada empresa}

Dada a importância do setor para a economia e a individualidade dos resultados apresentados e, para compreender melhor a relação entre CPV, DA, DV e RL deste segmento, apresentam-se na Tabela 3, os indicadores por empresa durante o período analisado, bem como suas respectivas médias e desvios padrões. O teste de Wilcoxon não pode ser aplicado devido ao tamanho da amostra, pois no período de 2010 a 2018, 
Custos das Empresas de Construção Civil listadas na B3 em períodos de Crise e de Prosperidade Econômica Guilherme Lima dos Santos, Valdemir da Silva, Cleiton Rodrigo Buarque Silva, Kleber Luis Alves Guedes, Natallya de Almeida Levino

apenas 04 informações por empresas foram coletadas, e na literatura não se possui valores de referências para amostras com $n<5$ observações.

Tabela 3

Indicadores auferidos por cada empresa listada do setor de construção civil da B3

\begin{tabular}{|c|c|c|c|c|c|c|c|}
\hline \multirow[t]{2}{*}{ Empresas } & \multirow[t]{2}{*}{ Relação } & \multicolumn{2}{|c|}{$\begin{array}{c}\text { Período } \\
\text { Total } \\
{[2010-2018]}\end{array}$} & \multicolumn{2}{|c|}{$\begin{array}{c}\text { Prosperidade } \\
\text { Econômica } \\
{[2010-2013]}\end{array}$} & \multicolumn{2}{|c|}{$\begin{array}{c}\text { Crise } \\
\text { Econômica } \\
{[2014-2018]}\end{array}$} \\
\hline & & Média & DP & Média & DP & Média & DP \\
\hline \multirow{4}{*}{ CONST A LIND } & $\mathrm{CPV} / \mathrm{RL}$ & 0,50 & 0,18 & $-0,52$ & 0,06 & $-0,49$ & 0,59 \\
\hline & $\mathrm{DA} / \mathrm{RL}$ & $-0,54$ & 0,44 & $-0,39$ & 0,16 & $-0,71$ & 0,60 \\
\hline & $\mathrm{DV} / \mathrm{RL}$ & 0,00 & 0,00 & 0,00 & 0,01 & 0,00 & 0,00 \\
\hline & $\mathrm{CT} / \mathrm{RL}$ & $-0,85$ & 0,50 & $-0,91$ & 0,17 & $-0,80$ & 0,73 \\
\hline \multirow{4}{*}{ TENDA } & $\mathrm{CPV} / \mathrm{RL}$ & $-0,63$ & 0,65 & $-0,55$ & 1,11 & $-0,70$ & 0,05 \\
\hline & $\mathrm{DA} / \mathrm{RL}$ & $-0,19$ & 0,04 & $-0,12$ & 0,05 & $-0,10$ & 0,03 \\
\hline & $\mathrm{DV} / \mathrm{RL}$ & $-0,11$ & 0,12 & $-0,17$ & 0,16 & $-0,05$ & 0,08 \\
\hline & $\mathrm{CT} / \mathrm{RL}$ & $-0,76$ & 0,72 & $-0,84$ & 1,24 & $-0,85$ & 0,14 \\
\hline \multirow{4}{*}{ CR2 } & $\mathrm{CPV} / \mathrm{RL}$ & $-0,72$ & 0,12 & $-0,72$ & 0,08 & $-0,73$ & 0,16 \\
\hline & $\mathrm{DA} / \mathrm{RL}$ & $-0,71$ & 0,57 & $-0,19$ & 0,10 & $-1,12$ & 0,50 \\
\hline & $\mathrm{DV} / \mathrm{RL}$ & $-0,09$ & 0,07 & $-0,07$ & 0,05 & $-0,10$ & $-0,10$ \\
\hline & $\mathrm{CT} / \mathrm{RL}$ & $-1,19$ & 0,61 & $-0,98$ & 0,16 & $-1,95$ & $-1,95$ \\
\hline \multirow{4}{*}{$\begin{array}{l}\text { CYRELA } \\
\text { REALT }\end{array}$} & CPV/RL & $-0,51$ & 0,53 & $-0,27$ & 0,85 & $-0,69$ & 0,04 \\
\hline & $\mathrm{DA} / \mathrm{RL}$ & $-0,10$ & 0,03 & $-0,07$ & 0,00 & $-0,12$ & 0,03 \\
\hline & $\mathrm{DV} / \mathrm{RL}$ & $-0,07$ & 0,07 & $-0,08$ & 0,00 & $-0,07$ & 0,10 \\
\hline & $\mathrm{CT} / \mathrm{RL}$ & $-0,67$ & $-0,67$ & $-0,43$ & 0,85 & $-0,87$ & 0,10 \\
\hline \multirow{4}{*}{ DIRECIONAL } & $\mathrm{CPV} / \mathrm{RL}$ & $-0,78$ & 0,08 & $-0,73$ & 0,04 & $-0,82$ & 0,09 \\
\hline & $\mathrm{DA} / \mathrm{RL}$ & $-0,08$ & 0,02 & $-0,07$ & 0,01 & $-0,09$ & 0,03 \\
\hline & $\mathrm{DV} / \mathrm{RL}$ & $-0,04$ & 0,02 & $-0,03$ & 0,00 & $-0,05$ & 0,03 \\
\hline & $\mathrm{CT} / \mathrm{RL}$ & $-0,90$ & 0,11 & $-0,83$ & 0,03 & $-0,96$ & 0,13 \\
\hline \multirow{4}{*}{ EVEN } & $\mathrm{CPV} / \mathrm{RL}$ & $-0,77$ & 0,06 & $-0,72$ & 0,01 & $-0,80$ & 0,06 \\
\hline & $\mathrm{DA} / \mathrm{RL}$ & $-0,08$ & 0,01 & $-0,07$ & 0,01 & $-0,09$ & 0,01 \\
\hline & $\mathrm{DV} / \mathrm{RL}$ & $-0,07$ & 0,02 & $-0,07$ & 0,01 & $-0,09$ & 0,01 \\
\hline & $\mathrm{CT} / \mathrm{RL}$ & $-0,92$ & 0,08 & $-0,84$ & 0,01 & $-0,98$ & 0,07 \\
\hline \multirow{4}{*}{ AZTEC } & $\mathrm{CPV} / \mathrm{RL}$ & $-0,52$ & 0,05 & $-0,50$ & 0,03 & $-0,54$ & 0,06 \\
\hline & $\mathrm{DA} / \mathrm{RL}$ & $-0,13$ & 0,04 & $-0,12$ & 0,03 & $-0,14$ & 0,05 \\
\hline & $\mathrm{DV} / \mathrm{RL}$ & $-0,06$ & 0,05 & $-0,02$ & 0,05 & $-0,09$ & 0,04 \\
\hline & $\mathrm{CT} / \mathrm{RL}$ & $-0,71$ & 0,13 & $-0,63$ & 0,06 & $-0,76$ & 0,15 \\
\hline
\end{tabular}


Custos das Empresas de Construção Civil listadas na B3 em períodos de Crise e de Prosperidade Econômica Guilherme Lima dos Santos, Valdemir da Silva, Cleiton Rodrigo Buarque Silva, Kleber Luis Alves Guedes, Natallya de Almeida Levino

\begin{tabular}{|c|c|c|c|c|c|c|c|}
\hline \multirow{4}{*}{ GAFISA } & $\mathrm{CPV} / \mathrm{RL}$ & $-0,88$ & 0,20 & $-0,78$ & 0,09 & $-0,96$ & 0,27 \\
\hline & $\mathrm{DA} / \mathrm{RL}$ & $-0,18$ & 0,03 & $-0,08$ & 0,01 & $-0,09$ & 0,04 \\
\hline & $\mathrm{DV} / \mathrm{RL}$ & $-0,07$ & 0,07 & $-0,09$ & 0,03 & $-0,05$ & 0,09 \\
\hline & $\mathrm{CT} / \mathrm{RL}$ & $-1,04$ & 0,23 & $-0,96$ & 0,12 & $-1,11$ & 0,32 \\
\hline \multirow{4}{*}{ HELBOR } & CPV/RL & $-0,81$ & 0,16 & $-0,70$ & 0,04 & $-0,90$ & 0,18 \\
\hline & $\mathrm{DA} / \mathrm{RL}$ & $-0,19$ & 0,05 & $-0,04$ & 0,00 & $-0,12$ & 0,06 \\
\hline & $\mathrm{DV} / \mathrm{RL}$ & $-0,07$ & 0,06 & $-0,04$ & 0,01 & $-0,27$ & 0,10 \\
\hline & $\mathrm{CT} / \mathrm{RL}$ & $-0,96$ & 0,31 & $-0,81$ & 0,04 & $-1,09$ & 0,33 \\
\hline \multirow{4}{*}{ JHSF PART } & $\mathrm{CPV} / \mathrm{RL}$ & $-0,55$ & 0,04 & $-0,56$ & 0,04 & $-0,55$ & 0,05 \\
\hline & $\mathrm{DA} / \mathrm{RL}$ & $-0,15$ & 0,08 & $-0,08$ & 0,02 & $-0,20$ & 0,08 \\
\hline & $\mathrm{DV} / \mathrm{RL}$ & $-0,05$ & 0,02 & $-0,07$ & 0,03 & $-0,04$ & 0,01 \\
\hline & $\mathrm{CT} / \mathrm{RL}$ & $-0,76$ & 0,08 & $-0,71$ & 0,05 & $-0,79$ & 0,10 \\
\hline \multirow{4}{*}{ JOAO FORTES } & $\mathrm{CPV} / \mathrm{RL}$ & $-1,03$ & 0,33 & $-0,74$ & 0,08 & $-1,26$ & 0,30 \\
\hline & $\mathrm{DA} / \mathrm{RL}$ & $-0,19$ & 0,12 & $-0,11$ & 0,02 & $-0,26$ & 0,15 \\
\hline & $\mathrm{DV} / \mathrm{RL}$ & $-0,14$ & 0,10 & $-0,07$ & 0,02 & $-0,19$ & 0,13 \\
\hline & $\mathrm{CT} / \mathrm{RL}$ & $-1,36$ & 0,54 & $-0,93$ & 0,11 & $-1,71$ & 0,56 \\
\hline \multirow{4}{*}{ MRV } & $\mathrm{CPV} / \mathrm{RL}$ & $-0,69$ & 0,02 & $-0,71$ & 0,03 & $-0,68$ & 0,02 \\
\hline & $\mathrm{DA} / \mathrm{RL}$ & $-0,06$ & 0,01 & $-0,05$ & 0,01 & $-0,06$ & 0,00 \\
\hline & $\mathrm{DV} / \mathrm{RL}$ & $-0,09$ & 0,02 & $-0,06$ & 0,01 & $-0,16$ & 0,01 \\
\hline & $\mathrm{CT} / \mathrm{RL}$ & $-0,84$ & 0,03 & $-0,82$ & 0,04 & $-1,18$ & 0,01 \\
\hline \multirow{4}{*}{ PDG REALT } & $\mathrm{CPV} / \mathrm{RL}$ & $-1,14$ & 1,03 & $-0,86$ & 0,22 & $-1,36$ & 1,49 \\
\hline & $\mathrm{DA} / \mathrm{RL}$ & $-0,25$ & 0,26 & $-0,08$ & 0,02 & $-0,38$ & 0,31 \\
\hline & $\mathrm{DV} / \mathrm{RL}$ & $-0,13$ & 0,16 & $-0,05$ & 0,01 & $-0,20$ & 0,22 \\
\hline & $\mathrm{CT} / \mathrm{RL}$ & $-1,52$ & 1,36 & $-0,99$ & 0,24 & $-1,94$ & 1,90 \\
\hline \multirow{4}{*}{$\mathrm{RNI}$} & $\mathrm{CPV} / \mathrm{RL}$ & $-0,77$ & 0,10 & $-0,71$ & 0,05 & $-0,81$ & 0,12 \\
\hline & $\mathrm{DA} / \mathrm{RL}$ & $-0,15$ & 0,05 & $-0,12$ & 0,01 & $-0,18$ & 0,05 \\
\hline & $\mathrm{DV} / \mathrm{RL}$ & $-0,09$ & 0,04 & $-0,05$ & 0,01 & $-0,11$ & 0,04 \\
\hline & $\mathrm{CT} / \mathrm{RL}$ & $-1,00$ & 0,17 & $-0,88$ & 0,04 & $-1,10$ & 0,18 \\
\hline \multirow{4}{*}{ ROSSI RESID } & CPV/RL & $-0,91$ & 0,17 & $-0,77$ & 0,04 & $-1,03$ & 0,18 \\
\hline & $\mathrm{DA} / \mathrm{RL}$ & $-0,16$ & 0,09 & $-0,09$ & 0,01 & $-0,22$ & 0,10 \\
\hline & $\mathrm{DV} / \mathrm{RL}$ & $-0,13$ & 0,07 & $-0,09$ & 0,01 & $-0,16$ & 0,09 \\
\hline & $\mathrm{CT} / \mathrm{RL}$ & $-1,20$ & 0,32 & $-0,95$ & 0,03 & $-1,40$ & 0,35 \\
\hline \multirow{4}{*}{ TECNISA } & $\mathrm{CPV} / \mathrm{RL}$ & $-0,92$ & 0,25 & $-0,76$ & 0,07 & $-1,05$ & 0,30 \\
\hline & $\mathrm{DA} / \mathrm{RL}$ & $-0,17$ & 0,10 & $-0,09$ & 0,02 & $-0,23$ & 0,11 \\
\hline & $\mathrm{DV} / \mathrm{RL}$ & $-0,07$ & 0,03 & $-0,06$ & 0,01 & $-0,08$ & 0,04 \\
\hline & $\mathrm{CT} / \mathrm{RL}$ & $-1,16$ & 0,37 & $-0,90$ & 0,10 & $-1,36$ & 0,43 \\
\hline TRISUL & CPV/RL & $-0,73$ & 0,05 & $-0,77$ & 0,05 & $-0,69$ & 0,03 \\
\hline
\end{tabular}


Custos das Empresas de Construção Civil listadas na B3 em períodos de Crise e de Prosperidade

Econômica

Guilherme Lima dos Santos, Valdemir da Silva, Cleiton Rodrigo Buarque Silva, Kleber Luis Alves Guedes,

Natallya de Almeida Levino

\begin{tabular}{cccccccc} 
& DA/RL & $-0,10$ & 0,03 & $-0,08$ & 0,01 & $-0,12$ & 0,02 \\
& DV/RL & $-0,08$ & 0,02 & $-0,06$ & 0,02 & $-0,09$ & 0,02 \\
& $\mathrm{CT} / \mathrm{RL}$ & $-0,90$ & 0,04 & $-0,91$ & 0,04 & $-0,90$ & 0,05 \\
\hline \multirow{3}{*}{ VIVER } & $\mathrm{CPV} / \mathrm{RL}$ & $-0,88$ & 1,54 & $-1,07$ & 0,39 & $-0,72$ & 2,27 \\
& $\mathrm{DA} / \mathrm{RL}$ & $-0,59$ & 1,69 & $-0,13$ & 0,07 & $-0,95$ & 2,46 \\
& $\mathrm{DV} / \mathrm{RL}$ & $-0,08$ & 0,19 & $-0,08$ & 0,04 & $-0,09$ & 0,28 \\
& $\mathrm{CT} / \mathrm{RL}$ & $-1,55$ & 3,08 & $-1,28$ & 0,47 & $-1,76$ & 4,59 \\
\hline
\end{tabular}

Nota. Fonte: Elaborado com base nos dados coletados da B3, 2019.

*Significância ao nível de 5\%; ** significância ao nível de $10 \%$.

Com base nos números descritivos apresentados na Tabela 3, verificam-se, nas seções seguintes, os resultados dos comportamentos revelados por cada indicador durantes o período total e os períodos de prosperidade e crise econômica.

\subsubsection{Comportamento dos Custos de Venda (CPV)}

Analisando por empresa a relação CPV/RL, constata-se que das 18 Companhias investigadas, apenas 5 (JHS Part, MRV, TRISUL, VIVER; CONST A LIND) não elevaram a média de participação dos custos de venda em relação às receitas líquidas durante o período analisado. Apesar da crise econômica, considerada entre 2014 e 2018, os dados revelaram que as 5 empresas reduziram o seu CPV.

As demais 13 empresas analisadas apresentaram uma evolução média dos custos de venda em relação à receita líquida. Esse comportamento significativamente evolutivo foi revelado, principalmente no período de crise econômica, para qual os dados mostram que a relação CPV/RL aumentou tanto em relação aos 4 anos (20102014) quanto em relação à série temporal (2010 a 2018). Isso indica que setores que abastecem o segmento da construção civil sentiram o impacto da crise, tendo, possivelmente, que aumentar o valor dos insumos consumidos pelo segmento em questão.

A análise descritiva mostra que, entre 2010 e 2018, para a relação CPV/RL, a empresa que apresentou a maior média foi a PDG REALT com um índice de 1,14 e 
Custos das Empresas de Construção Civil listadas na B3 em períodos de Crise e de Prosperidade Econômica Guilherme Lima dos Santos, Valdemir da Silva, Cleiton Rodrigo Buarque Silva, Kleber Luis Alves Guedes, Natallya de Almeida Levino

( $d p \pm 1,03)$; a segunda maior média foi revelada pela JOÃO FORTES que apresentou o índice médio de 1,03 ( $d p \pm 0,33$ ). As menores médias da relação $C P V / R L$ foram das empresas CONST A LIND, com índice de 0,50 (dp $\pm 0,18)$, e CYRELLA REALT, com índice de 0,51 (dp $\pm 0,53)$.

No período de crise econômica, as empresas que apresentaram as maiores médias de evolução de comprometimento da RL com o CPV foram em decrescente as seguintes: a PDG REALT, com média de 1,36 ( $\mathrm{dp} \pm 1,49$ ); JOÃO FORTES, média de 1,26 ( $d p \pm 0,30$ ); TECNISA, com média de 1,05 ( $d p \pm 0,30$ ); e ROSSI RESID, com média de 1,03 ( $d p \pm 0,18)$. Essas quatro empresas apresentaram as maiores médias tanto entre 2010 e 2018 quanto nos períodos pré-crise (2010-2014) e durante a crise (2014-2018).

\subsubsection{Comportamento das Despesas Administrativas}

A relação entre as despesas administrativas (DA) e a receita líquida $(R L)$ entre 2010 e 2018 mostra que apenas 4 empresas (HELBOR, GAFISA, MRV e TENDA) não aumentaram o índice DA/RL. Com as exceções da MRV e da GAFISA - que mantiveram praticamente a mesma performance média entre os oito períodos analisados e também durante os quatro anos do período de crise econômica - observase que a HELBOR e a TENDA reduziram exitosamente a média de comprometimento dos seus gastos administrativos em relação à receita líquida realizada. Tais empresas mostraram adequação administrativa à crise, mantendo uma eficiente estrutura de custos fixos.

Entretanto, as outras 14 empresas analisadas aumentaram o nível de comprometimento dos gastos administrativos em relação as receitas líquidas realizadas entre os períodos de prosperidade econômica e de crise econômica. Os resultados também revelam que essas 14 companhias apresentam um índice $D A / R L$, durante o período de crise econômica, bem maior do que os oito anos analisados. Essa evolução de comprometimento dos gastos administrativos diante das receitas líquidas pode 
Custos das Empresas de Construção Civil listadas na B3 em períodos de Crise e de Prosperidade Econômica Guilherme Lima dos Santos, Valdemir da Silva, Cleiton Rodrigo Buarque Silva, Kleber Luis Alves Guedes, Natallya de Almeida Levino

indicar o declínio das receitas e a manutenção de gastos fixos administrativos que existem independentemente do nível de vendas dessas companhias.

As maiores médias do índice do DA/RL foram para as empresas CR2, VIVER e CONST A LIND. Durante o período de prosperidade econômica, os resultados médios mostram que as maiores médias foram em ordem decrescente para as seguintes entidades: CONST A LIND, com 0,39 (dp $\pm 0,16)$; CR 2, 0,19 (dp $\pm 0,10)$; e VIVER, com 0,13 ( $d p \pm 0,07$ ). Para o período de crise econômica, os resultados médios mostram que as maiores médias foram: CR 2, com 1,12 ( $\mathrm{dp} \pm 0,50)$; VIVER, com 0,95 ( $\mathrm{dp} \pm 2,46)$; e CONST A LIND, com 0,71 (dp $\pm 0,60)$. Para série temporal investigada (2010-2018) as mesmas companhias apresentaram as maiores médias.

\subsubsection{Comportamento das Despesas de Vendas}

Os resultados médios da relação entre as despesas de vendas (DV) e a receita líquida (RL) mostram que apenas 3 companhias (TECNISA, CYRELLA REALT, GAFISA e JHSF PART) conseguiram reduzir a absorção média dos gastos de vendas diante das receitas líquidas entre os períodos de prosperidade econômica e de crise econômica. Entretanto, as demais companhias elevaram o índice DV/RL tanto entre os oito anos analisados, quanto entre os períodos de prosperidade e de crise econômica. Isso indica que, mesmo havendo uma retração econômica, apontando o declínio de receitas de vendas, alguns gastos com vendas inclinaram, demonstrando o comportamento adverso.

Nos 8 anos investigados, as menores médias da relação DV/RL foram em ordem crescente das seguintes empresas: JHSF PART, com índice de $0,04(\mathrm{dp} \pm 0,1)$; TENDA, com 0,05 ( $\mathrm{dp} \pm 0,8)$; e CYRELLA REALT, com 0,77 ( $\mathrm{dp} \pm 0,10)$. Adversamente, as maiores médias foram em ordem decrescente, apresentadas pelas seguintes companhias: HELBOR com o índice de 0,27 ( $d p \pm 0,10)$; PDG REALT, com 0,20 $(\mathrm{dp} \pm 0,22)$; e JOÃO FORTES com $0,19(\mathrm{dp} \pm 0,13)$. 
Custos das Empresas de Construção Civil listadas na B3 em períodos de Crise e de Prosperidade Econômica Guilherme Lima dos Santos, Valdemir da Silva, Cleiton Rodrigo Buarque Silva, Kleber Luis Alves Guedes, Natallya de Almeida Levino

\subsubsection{Comportamento dos Custos Totais}

Análise dos custos totais em relação às receitas totais mostra claramente o impacto da crise econômica no comportamento evolutivo dos gastos entre o período de prosperidade econômica e o de crise econômica. Os resultados encontrados para o índice CT/RL revelam que apenas duas empresas (CONST A LIND e TRISUL) apresentaram redução dos custos totais, entretanto, as outras 16 companhias apresentaram em suas demonstrações de resultado um comportamento progressivo e adverso ao desempenho econômico destas entidades, pois os seus custos totais aumentaram.

Entre os períodos de prosperidade econômica e o de crise econômica, os resultados mostram que 10 empresas apresentaram o índice $C T / R L$ superior a unidade, indicando claramente resultados negativos. As companhias que apresentaram as maiores médias foram as seguintes: PDG REALT com índice de 1,94 ( $d p \pm 1,94)$; VIVER, com 1,76 ( $d p \pm 4,59)$; e JOÃO FORTES ( $d p \pm 0,56)$.

Para os oitos períodos analisados, os resultados da relação $C T / R L$ demonstraram que as maiores médias também foram das empresas VIVER, PDG REALT e JOÃO FORTES.

Quando observado os dados das empresas separadamente, nota-se que, em geral, há uma provável perda de desempenho operacional pelas entidades no período de crise econômica, quando as médias da relação CPV/RL, DA/RL, DV/RL e CT/RLV, em ambos os períodos são estatisticamente diferentes para uma ou outra empresa nos casos em que houve significância estatística, seja ao nível de $5 \%$ ou $10 \%$.

\section{CONSIDERAÇÕES FINAIS}

A gestão de custos é essencial para a obtenção de bons resultados empresariais, pois torna as empresas mais competitivas dentro de um mercado que exige excelência para cada atividade desenvolvida, além de possibilitar previsões de 
Custos das Empresas de Construção Civil listadas na B3 em períodos de Crise e de Prosperidade Econômica Guilherme Lima dos Santos, Valdemir da Silva, Cleiton Rodrigo Buarque Silva, Kleber Luis Alves Guedes, Natallya de Almeida Levino

desempenhos. A primazia relacionada à gestão de custos é ainda mais relevante dentro do setor da construção civil, já que o produto das suas atividades é atrelado a processos de médio e longo prazo, e uma deficiência no gerenciamento de custos pode significar resultados decepcionantes.

A pesquisa objetivou investigar como se comportam os custos das empresas da construção civil antes e durante a crise econômica que se instalou no Brasil a partir de 2013, observando a intensidade das mudanças dos valores médios dos quatro tipos de indicadores custos investigados - CPV/RL, DV/RL, DA/RL e CT/RL - nos dois cenários econômicos, durante o período observado, utilizando-se para isso das informações contábeis de 18 empresas listadas na B3.

Os achados da pesquisa mostram a importância de analisar o comportamento dos custos e, considerando os quatro indicadores de custos analisados, os resultados identificados mediante a estatística descritiva e teste de soma de postos (W de Wilcoxon) indicam que, em períodos de crise econômica, três dos quatro indicadores de custos, em geral, cresceram no conjunto das 18 empresas analisadas, mostrando para os dois períodos analisados o possível declínio das receitas e manutenção dos custos fixos estruturais.

Com isso, as empresas, com custo de produção vendida - CPV/RL - superiores a 1,0, quando comparadas aos períodos de prosperidade econômica apresentaram resultados negativos. Para os dois cenários analisados essa situação foi evidenciada, sobretudo, nos comportamentos das relações $D A / R L$ que passou de 0,11 para 0,32, um crescimento de $185 \%$. Esses resultados apontam o declínio dos resultados e principalmente prejuízos em 10 empresas analisadas.

Ressalta-se que, por mais que haja algumas similaridades, em geral, o comportamento dos custos diverge entre as empresas do setor, pois, apesar dos declínios evidenciados pelos quatros indicadores de custos para as 18 empresas, observou-se que 5 delas não elevaram a média de participação dos custos de venda em relação às receitas líquidas $-C P V / R L-e$, quanto à relação entre os custos totais $e$ 
Custos das Empresas de Construção Civil listadas na B3 em períodos de Crise e de Prosperidade Econômica Guilherme Lima dos Santos, Valdemir da Silva, Cleiton Rodrigo Buarque Silva, Kleber Luis Alves Guedes, Natallya de Almeida Levino

às receitas líquidas $-C T / R L$ - 2 empresas conseguiram reduzir essa relação, enquanto que 16 revelaram um comportamento progressivo e adverso, das quais 10 apresentaram os custos totais superiores às receitas. Com isso, torna-se importante investigar as peculiaridades da estrutura de custos de cada empresa.

Os resultados revelados por esta pesquisa trazem contribuições que são de interesse para inúmeros usuários da informação contábil, entre eles gestores e investidores (e potenciais investidores) e credores, os quais, analisando o comportamento dos custos, sobretudo, em períodos de recessão econômica podem encontrar caminhos que sinalizam uma tomada de decisão mais assegurada, buscando manter a continuidade das operações no mercado.

Certo de que este estudo não exaure as investigações sobre o comportamento dos custos e considerando abrangência do assunto, sugere-se a importância do desenvolvimento de novas pesquisas em outros setores da B3 (Saúde, Energia, Agronegócio entre outros), buscando correlacionar variáveis como o tamanho dos ativos fixos e dos os custos de mão de obra a fim de explicar o comportamento dos custos das empresas.

\section{REFERÊNCIAS}

Araújo, D. C., Mendes, J. A. N., \& Martins, R. Z. (2018). Gestão de custos aplicada à indústria de Estruturas pré-moldadas utilizadas em construção civil de condomínios: estudo de caso. Revista H-TEC Humanidades e Tecnologia, 2(2), 115-127.

Bomfim, E. T., Callado, A. A. C., \& Callado, A. L. C. (2018, novembro). Aspectos do custeio alvo na gestão de custos: um estudo em micro e pequenas empresas do setor de informática e tecnologia de Campina Grande-PB. Congresso Brasileiro de Custos. Vitória, Espírito Santo, Brasil, 15.

Bradbury, M. E., \& Scott, T. (2013). Do managers understand asymmetric cost behavior. Unpublished working paper. Available at http://papers. ssrn. com/sol3/papers. cfm. 
Custos das Empresas de Construção Civil listadas na B3 em períodos de Crise e de Prosperidade Econômica

Guilherme Lima dos Santos, Valdemir da Silva, Cleiton Rodrigo Buarque Silva, Kleber Luis Alves Guedes, Natallya de Almeida Levino

Callado, A. A. C., \& de Pinho, M. A. B. (2014). Evidências de isomorfismo mimético sobre práticas de gestão de custos entre micro e pequenas empresas de diferentes setores de atividade. Revista Contabilidade Vista \& Revista, 25(2), 119-137.

Câmara Brasileira da Indústria da Construção. (2020). PIB Brasil e Construção Civil. Recuperado de: http://www.cbicdados.com.br/menu/pib-e-investimento/pib-brasil-econstrucao-civil

Ezekiel, A., Adebayo, A. O., \& Osemense, O. (2019). Impact of strategic cost management pratices on organisational performance of selected manufaturing firms in nigeria. IGBR. Institute for Global Busines Research, Nashville

Fernandes, C. E. N., Matsuoka, J. V., \& Costa, E. S. (2018) Avalição do sistema de gestão de qualidade utilizando o MCC - Manutenção Centrada na Confiabilidade na análise de falhas da construção civil. Revista GETEV - Gestão Tecnologia e Ciências, 7(19), 72-92.

Garrison, R. H., Noreen, E. W., \& Brewer, P. C. (2013). Contabilidade Gerencial. São Paulo, AMGH Editora Ltda.

Instituto Brasileiro de Geografia e Estatística. (2020). Desemprego / IBGE. Recuperado de: https://www.ibge.gov.br/explica/desemprego.php

Kripla, R. M. L., Scheller, M., \& Bonotto, D. L. (2015) Pesquisa Documental: Considerações sobre conceitos e características na Pesquisa Qualitativa. Investigação Qualitativa em Educação, 2, 243-247.

Ludwing, M. J., Borgert, A., \& Kremer, A. W. (2016) Desoneração da folha de pagamento e comportamentos dos custos em empresas da Construção Civil. Pensar Contábil, 18(66), 14-23.

Machado, D. G., \& Souza, M. A. (2006) Análise das relações entre a gestão de custos e a gestão do preço de venda: Um estudo das práticas adotadas por empresas industriais conserveiras estabelecidas no RS. Revista Universo Contábil, 2(1), 4260 .

Magalhães, R. A., Elias, T. M., Ferreira, L. F., \& Borgert, A. (2017). Desoneração previdenciária e o comportamento dos custos das empresas de calçados listadas na BM\&FBOVESPA. ABCustos, 12(1), 47-71.

Martins, E. (2003). Contabilidade de Custos. São Paulo, Editora Atlas. 
Custos das Empresas de Construção Civil listadas na B3 em períodos de Crise e de Prosperidade Econômica

Guilherme Lima dos Santos, Valdemir da Silva, Cleiton Rodrigo Buarque Silva, Kleber Luis Alves Guedes, Natallya de Almeida Levino

Medeiros, O. R., Costa, P. S., \& Silva, C. A. T. (2005) Testes empíricos sobre o comportamento assimétrico dos custos nas empresas brasileiras. Revista Contabilidade e Finanças. São Paulo, 16(38), 47-56.

De Oliveira, A. C., David, B. V., da Silva, V., Guedes, K. L. A., \& Correia, J. J. A. (2019). Comportamento dos Custos das Empresas de Construção Civil Listadas na B3 entre 2008 e 2017. ABCustos, 14(2), 70-95.

Pádua, E. M. M. (2012). Metodologia da Pesquisa Abordagem Teórico-Prática. Campinas, Paripus Editora.

Paiva, P. A., \& Ribeiro, M. A. (2005) A reciclagem na construção civil: como economia de custos. Revista Eletrônica de Administração, 1(13), 38-53.

Pamplona, E., Leite, M., \& Zonatto, V. C. S. (2018). Fatores associados ao comportamento dos custos em períodos de prosperidade e crise econômica em empresas dos países que compõe o PIIGS. Estudios Gerenciales: Journal of Management and Economics for Iberoamerica, 34(148), 305-319.

Paulino, J. O. (2012). Implantação do controle de custos na empresa Doce Mais. Pedro Leopoldo, Fundação Pedro Leopoldo.

Richartz, F. (2013). O comportamento dos custos das empresas brasileiras listadas na BM\&FBovespa entre 1994 e 2011. (Dissertação de Mestrado). Universidade Federal de Santa Catarina - UFSC, Florianópolis, Santa Catarina, Brasil.

Richartz, F., Borgert, A., \& Lunkes, R. J. (2014) Comportamento assimétrico dos custos nas empresas brasileiras listadas na BM\&FBovespa. ASAA Journal, 7(3), 339-361.

Rigo, V. P., Godoy, N. N., \& Scarpin, J. E. (2015) Comportamento dos Custos nas Empresas do Segmento de alimentos Listadas na BM\&FBOVESPA. ABCustos, 10(2), 20-45.

Scramin, M. A. M. (2012). Adoção do IFRS e CPCs no reconhecimento da receita e despesa em empresas de construção civil do ramo imobiliário: Efeitos na qualidade das informações contábeis. (Dissertação de Mestrado). Pontifícia Universidade Católica de São Paulo - PUC, São Paulo, SP, Brasil.

Serrado, I., Santos, J., Oliveira, N., Jesus, V., \& Netto, J. (2017) Análise dos Fatores de Risco de Mercado em Empreendimentos de Construção Civil. SEGeT-Simpósio de Excelência em Gestão e Tecnologia, Resende, RJ, Brasil, 14. 
Silva, A. D., Zonatto, V. C. D. S., Magro, C. B. D., \& Klann, R. (2019). Comportamento assimétrico dos custos e gerenciamento de resultados. BBR. Brazilian Business Review, 16(2), 191-206. https://doi.org/10.15728/bbr.2019.16.2.6

Silva, I. F. U., Leal, E. A., \& Trindade, J. A. S. (2015) Comportamento dos custos nas empresas listadas na BM\&F Bovespa do segmento de carnes e derivados nos anos de 2004 a 2013. ABCustos Associação Brasileira de Custos, 10(1), 90-108.

Souza, B. A., Oliveira, C. A. C., Santana, J. C. O., Viana Neto, L. A. C., \& Santos, D. G. (2015) Análise dos indicadores PIB Nacional e PIB da Construção Civil. RDE Revista de Desenvolvimento Econômico, 17(31), 140-150.

Vanderbeck, E. J., \& Nagy, C. F. (2001). Contabilidade de custos. (11a ed.). São Paulo, Pioneira.

Vieira, B. A., \& Nogueira, L. (2018) Construção civil: Crescimento versus custos de produção civil. Sistema \& Gestão Revista Eletrônica, 13(3), 366-377.

Xavier Filho, J. L. J. (2019). Desenvolvendo tecnologia de gestão via pesquisa-ação: Uma forma alternativa de demonstrar o resultado tendo por base o custeio variável. Congresso Brasileiro de Custos. Curitiba, Paraná, Brasil, 26.

Data de Submissão: 28/05/2020

Data de Aceite: 09/04/2021 